\title{
The Relationship Between Quality of Work Life and Employees Improvement in Keshavarzi Banks of Saveh,iran
}

\author{
${ }^{1}$ Akram vali, ${ }^{2}$ Zeinolabedin amini sabegh, ${ }^{3}$ Reza shafizadeh \\ ${ }^{I}$ Student of Public management, Science and Research branch, Islamic Azad University, Saveh, Iran. \\ ${ }^{2,3}$ Departmen ${ }^{t}$ of Public management, Science and Research branch, Islamic Azad University, Saveh, Iran
}

\begin{abstract}
This study was conducted with aims of representing the relationship between Quality of work life and employees improvement in keshavarzi banks of saveh city in the years of 2013. The pollution of research was including 125 employee involved in keshavarzi banks of saveh city and among whom, 95 people was considered as sample by using Cochran formula and random sampling method. Data collection was carried out through Walton(1973) questionnaire, and made researcher of employees improvement questionnaire. questionnaires reliability by using of Alpha Chronbach method obtained 0.81 for QWL questionnaire and 0.85 for made researcher of employees improvement questionnaire. Also to measure of questionnaires validity, used Content validity that for this reason questionnaires confirmed by specialists. Data analysis was carried out through SPSS 20 and Lisrel 8.8 software in two aspects of descriptive (frequency, frequency percentage, mean, Standard deviation) and inferential (Structural Equation Modeling, K-S Test, Pearson correlation coefficient, Ranking Fridman test, Simple and multi-variable linear regression). The results showed that there is a significant relationship between QWL and it's dimensions (Fair pay, working conditions of safe and health care, legalism, providing opportunities for continued growth and security, social dependence, personal skills development, total space of work and social integration) with employees improvement.
\end{abstract}

Keywords: QWL, employees improvement, Fair pay, legalism

\section{Introduction}

The world of industrialized era has traditionally placed an emphasis on technology advancement, productivity and growth, and human beings have either implicitly or explicitly been regarded together with land and capital as one of the desirable production inputs, whereas the way they are looked at by the literature of evolution management appears to be applied. That is, human beings serve as both labor actor and creator. A pivotal role, therefore, is played by them in the evolution of organizations to the extent that huge organizational evolutions have been sprung from their limitless intellectual competences. The concept of the quality of work life (QWL) has been recently converted into a major social issue all around the world, while the importance of (non-work) personal life was traditionally underlined. In today's societies the quality of work life has emerged as one of the most important goals of a given organization and its staff members. When these staff members are treated respectfully and given opportunities to express their latent opinions and to participate in decision making process, they in return reveal more desirable reactions. If a staff member has a feeling that his QWL has really improved, he will find himself more powerful to discharge the work assigned and consequently be injected with more motivation for a better output. And all this will result in a much higher quality of his work life.

Some scholars are of the opinion that part of a decrease in productivity and in products quality experiencedby industrialized countries can be attributed to deficits in the work life quality and to the changes that have recently occurred in staffers' interests and attitudes. Presently, staff members expect to be given more chances of participation in and supervision over their own work. If human force employed by an organization is paid possibly more attention to, they will play an important critical role in achieving organizational goals. Therefore, employing various methods and techniques to promote the quality of work life can be justified and seen as a useful step to be taken with this regard.

\section{Problem Statement}

So far no production process has been invented to appear needless of human labor and that is why no production can be performed in the absence ofhuman involvement. However, involvement of human resources in societies' historical development and evolution has seen to itself both quantitative and qualitative changes in human labor within the field of production. The role human force serves has reached from physical labor to its most advanced state (i.e. the state in which human force provides more of thought while machineproduces more of labor). Industrial development is realized through reliance on two important types of capital: physical capital and human capital. What has lately drawn more attention in advanced countries is the human capital. Human resources operate two major roles in economical production and growth: one is acting as a primary factor of production and the other as a factor transcending labor and other factors of production. 
In today's world, labor is no longer regarded as a quantitative factor in production and development, rather the quality and efficiency of labor force and their enhancement, owing to the effects and results they bring about, receive more attention. As generally witnessed, the huge advancement by Japan during post World War II years was primarily a result of this country'sreliance on its rich human capital rather than on either a capital imported from outside or its other resources.

In improving the quality of work life, a proper definition of this concept is required to serve as a basis for a dynamic analysis. According to Walton, a program to boost the quality of work life in a given organization encompasses any self-improvement in its organizational culture which supports and encourages growth and excellence of its staffers. In the value system of work life quality, therefore, making investments on members is regarded as a variable of the highest importance in the field of strategy management. This system of value includes the below dimensions:

Fair and adequate compensation, safe and healthy working conditions, occupational promotion, making use of employees' knowledge, skills and capabilities, social conditions of work environment, balance between work and non-work life, support of employees' rights, andassignment ofresponsibilities.

In his investigation into the relationship between the quality of work life (QWL) and performance of workers' social security in Mazandaran Province, Hoseini found a significant association between QWL and worker's social performance.

On the other hand, the term 'self-improvement' was first introduced in the writings and belief system of mercantilist thinkers. How this term found its way into the literature of economy stills remains controversial. To provide a definition for 'self-improvement,' first we need to define efficiency and effectiveness. Employees' output in a certain period of time is called 'efficiency' and the extent to which organizational goals are achieved is referred to as effectiveness. Efficiency and effectiveness when added up create self-improvementwhich has the following dimensions to it: staff-level self-improvement, organization-level self-improvement, economic sector-level self-improvement, and national-level self-improvement.

George conducted a study investigating the effects of job stress and job satisfaction on performance. He concluded that the more job stress increases the less self-improvement is made and vice versa .

There is an acceptable example indicating that advancements resulted from the quality of work life exert desirable effects on the organization's performance and self-improvement. In another study, it was reported that QWL factors influence the self-improvement of public servants. Most QWL programs are intended to enhance, through promoting the level of employees' motivation, their job satisfaction, performance and other related factors.

Bearing the above in mind, this study attempts to come up with an effective instrument to investigate various dimensions of the quality of work life and then to determine proper strategies to promote QWL and ultimately the organizational and individual self-improvement. In addition, this instrumentwill be designed to measure the extent to which managers are acquainted with the concept of work life quality and selfimprovement and to see whether they can draw a distinction between self-improvement and effectiveness and efficiency. Based on the above definitions, the researchers seeks a relationship between the quality of work life (QWL) and the self-improvement of people working for Keshavarzi Bank in Saveh township, Iran.

\section{Hypothesizes \\ Main hypothesis}

There is a statistically significant relationship between the employees' quality of work life and self-

Sub-hypotheses improvement.

1. There is a statistically significant relationship between fair and adequate compensation and selfimprovement of the employees.

2. There is a statistically significant relationship between safe and healthy working conditions and selfimprovement of the employees.

3. There is a statistically significant relationship between constitutionlizationand self-improvement of the employees.

4. There is a statistically significant relationship between the availability of opportunities for growth and constant security and self-improvement of the employees.

5. There is a statistically significant relationship between the employees' social reliance and selfimprovement.

6. There is a statistically significant relationship between the employees' development of personal competences and self-improvement.

7. There is a statistically significant relationship between total life space and self-improvementof the employees. 
8. There is a statistically significant relationship between social integration and selfimprovementof the employees.

\section{Research Methodology}

The present research due to its effort to investigate the association between the employees' quality of work life and self-improvementcan be classified as a descriptive-survey as well as a correlational study. In a correlational study the researcher does not manipulate an independent variable to see its effect(s) on dependent variable(s), rather he selects two variables to investigate their reciprocal impact on each other i.e. covariance within a sample under study. In terms of objective, this study can be considered as applied research. The present study has been carried out in branches of Keshavarzi Bank with its working human resources amounting to a total of 125 people in Saveh Township, Iran.The statistical population of this study consisted of all employees including the Bank's managers, deputies and clerks.

\section{Instrumentation}

In order to discharge the objectives of this study, the following instruments were made use of:

A. General (anthropological)inventory which was designed to collect general anthropological data on respondents, and

B. Specialized inventoryconsisting of 80 items. In designing this inventory, it was tried to make items as clear and understandable as possible. In addition, some items were also phrased in the reverse. Theses reversely phrased items, when being fed to the statistical analysis software, were reverse-scored via encryption.

\section{Reliability}

By reliability we mean to reach a similar, accurate and reliable set of results if the under-study variable is retested under the same conditions with the same scale(s) administered to other respondents of similar particulars to those of the main respondents. Since this study utilized a Likert-type scale and it couldindeed be regarded as a kind of attitude assessment, the most appropriate method to calculate reliability appeared to be Cronbach's alpha. For the questionnaires gathered from a number of 120 respondents, the Cronbach's alpha coefficient was calculated 0.89 .

\section{Hypothesizes Test}

Sub-hypothesis 1: There is a statistically significant relationship between fair and adequate compensation and self-improvement of the employees.

Table 1 presents the results of a correlational test carried out for sub-hypothesis 1.

Table1 Correlation matrix between the two constructsof the sub-hypothesis 1

\begin{tabular}{cccc}
\hline Constructs & Fair compensation & Self-improvement & Level of significance \\
\hline Fair compensation & 1 & 0.61 & 0.000 \\
Self-improvement & 0.61 & 1 & 0.000 \\
\hline
\end{tabular}

Since for thiscorrelation matrix, the level of significance falls below the level of error (0.05), H0 is rejected and $\mathrm{H} 1$ is maintained at the level of confidence $95 \%$. That is, the correlation the employees' fair compensation has with their self-improvementis suggested to be statistically significant. The positive sign of the correlation coefficient calculated $(+0.61)$ implies a direct correlation between the two constructs. Put it another way, the fairer the employees' compensation becomes, the more their creativity develops.

Sub-hypothesis 2: There is a statistically significant relationship between safe and healthy working conditions and self-improvement of the employees.

Table 2 provides the results of a correlational test carried out for sub-hypothesis 2 .

Table 2: Correlation matrix between the two constructs of the sub-hypothesis 2

\begin{tabular}{cccc}
\hline Constructs & $\begin{array}{c}\text { Safe and healthy work } \\
\text { environment }\end{array}$ & Self-improvement & Level of significance \\
\hline $\begin{array}{c}\text { Safe and healthy work } \\
\text { environment } \\
\text { Self-improvement }\end{array}$ & 1 & 0.65 & 0.003 \\
\hline
\end{tabular}

Again here, the level of significance appears to be less than the level of error (0.05). At the level of confidence $95 \%$ consequently $\mathrm{H} 0$ is rejected, while $\mathrm{H} 1$ is maintained. In other words, a statistically significant correlation is 
reported between the employees' safe and healthy work environment and their self-improvement. Further, the positive sign of the obtained correlation coefficient $(+0.65)$ signifies the positive direct role of safe and healthy work environment in enhancing the staff members' creativity.

Sub-hypothesis 3: There is a statistically significant relationship between constitutionlization and selfimprovement of the employees.

The results obtained from a correlational testing of the sub-hypothesis 3 are illustrated by Table 3 .

Table 3: Correlation matrixfor the two constructs of the sub-hypothesis 3

\begin{tabular}{cccc}
\hline Constructs & Constitutionalization & Self-improvement & Level of significance \\
\hline Constitutionalization & 1 & 0.69 & 0.001 \\
Self-improvement & 0.69 & 1 & 0.001 \\
\hline
\end{tabular}

As can be seen from the above table, the level of significance is below the level of error (0.05), therefore, considering the level of confidence (95\%) it can be concluded that $\mathrm{H} 0$ is rejected and $\mathrm{H} 1$ is maintained. That is, a statistically significant correlation is found between constitutionalization and self-improvement of the staffers. In addition, +0.69 as the correlation coefficient of the sub-hypothesis 3 signals a direct positive correlation between these two constructs. As such, if constitutionalization is reinforced among the employees, this will result in their greaterself-improvement.

Sub-hypothesis 4: There is a statistically significant relationship between the availability of opportunities for growth and constant security and self-improvement of the employees.

As shown by Table 4.7., the results from testing the sub-hypothesis 4 suggest thatthe availability of growth opportunities and constant security for the employees significantly directly correlates with their selfimprovement. Table 4.7 illustrates results of the correlational testing performed for the sub-hypothesis 4.

Table4: Correlation matrix for the two constructs of the sub-hypothesis 4

\begin{tabular}{cccc}
\hline Constructs & Courage & Self-improvement & Level of significance \\
\hline Courage & 1 & 0.61 & 0.000 \\
Self-improvement & 0.61 & 1 & 0.000 \\
\hline
\end{tabular}

Owing to the level of significance falling below the test's level of error (0.05), a significant, direct correlation between the recent two constructs can be concluded. That is, greaterself-improvement of employees may be expected if they are provided with opportunities for growth and development.

Sub-hypothesis 5: There is a statistically significant relationship between the employees' social reliance and self-improvement.

As can be seen from Table 4.8, the results obtained here suggest that there is a statistically significant, direct correlation between the staff members' social reliance and self-improvement.

Table5: Correlation matrix for the two constructs of the sub-hypothesis 5

\begin{tabular}{cccc}
\hline Constructs & Fair compensation & Self-improvement & Level of significance \\
\hline Social reliance & 1 & 0.71 & 0.000 \\
Self-improvement & 0.71 & 1 & 0.000 \\
\hline
\end{tabular}

According to the above table, since the level of significance remains less than the test's level of error (0.05), it can be concluded that these two constructs correlate both statistically significant and directly. In other words, the more the staff members' communications stemming from their social reliance develop, the greater their selfimprovement will be.

Sub-hypothesis 6: There is a statistically significant relationship between the employees' development of personal competences and self-improvement.

The results achieved from the correlational testing of the sub-hypothesis 6 reveal a statistically significant, direct correlation between development of personal competences and self-improvement of the employees working in variousKeshavarzi Bank branches in Saveh Township. Table 6 presents these results.

Table6: Correlation matrix for the two constructs of the sub-hypothesis 6

\begin{tabular}{cccc}
\hline Constructs & $\begin{array}{c}\text { Development of personal } \\
\text { competences }\end{array}$ & Self-improvement & Level of significance \\
\hline $\begin{array}{c}\text { Development of personal } \\
\text { competences }\end{array}$ & 1 & 0.77 & 0.000 \\
Self-improvement & 0.77 & 1 & 0.000 \\
\hline
\end{tabular}


Here again, due to the level of significance emerging to be less than the level of error (0.05), a statistically significant, direct correlation can be concluded to exist between the above two constructs. This implies that by helping skills and competences of Bank staffers develop, anself-improvement of higher degrees may be expected in them.

Sub-hypothesis 7: There is a statistically significant relationship between total life space and self-improvement of the employees.

As shown by Table 4.10, the results from testing this sub-hypothesis signify again a significant, direct correlation between total life space and self-improvement of the Bank employees. These results are illustrated by Table 7 .

Table7: Correlation matrix for the two constructs of the sub-hypothesis 7

\begin{tabular}{cccc}
\hline Constructs & Total life space & Self-improvement & Level of significance \\
\hline Total life space & 1 & 0.73 & 0.001 \\
Self-improvement & 0.73 & 1 & 0.001 \\
\hline
\end{tabular}

As can be seen from Table 4.10, the level of significance which appears to be less than level of error $(0.05)$ signifies a significant, direct correlation. Briefly put, any promotion of total life space will possibly lead to a greater self-improvement.

Sub-hypothesis 8: There is a statistically significant relationship between social integration and selfimprovement of the employees.

The findings from this hypothesis' correlational testing suggest a significant, direct correlation between social integration and self-improvement of the Bank employees. These results are presented by Table 8 .

Table8: Correlation matrix for the two constructs of the sub-hypothesis 8

\begin{tabular}{cccc}
\hline Constructs & Social integration & Self-improvement & Level of significance \\
\hline Social integration & 1 & 0.68 & 0.000 \\
Self-improvement & 0.68 & 1 & 0.000 \\
\hline
\end{tabular}

As shown by Table 8, the results obtained reveal that level of significance falls below the level of error (0.05). That is, the correlation between these two constructs is both statistically significant and direct. Put it another way, social integration of the Bank employees directly correlates with their self-improvement.

\section{Examination of the Research Hypotheses by means of Structural Equations}

The research hypotheses of this study were examined via a structural model. The results obtained from LISREL software suggest the employees' quality of work life significantly directly correlates with their selfimprovement. Further, according to the standardized coefficients from LISREL software there can be seen a direct correlation of $70 \%$ between these two constructs. The difference observed between the recent value and that from correlational testing by SPSS software can be attributed to a measurement error which has also been calculated by SEM software; therefore, factor coefficient appears to be closer to reality.

The output from LISREL software is in agreement with the research sub-hypotheses, as illustrated by the following table. If $t$-values are observed to be either greater than +1.96 or less than -1.96 ; this implies the respective parameter's statistically significance. Accordingly, the t-values given by Table 4.16 signify the statistically significance of the relationships set out by this study's main and sub-hypotheses.

Table 9:.Findings from testing the research hypotheses

\begin{tabular}{|c|c|c|c|}
\hline Hypothesis & Standardized coefficient & Value of t-statistic & Findings \\
\hline $\begin{array}{c}\text { The quality of work life ....self- } \\
\text { improvement }\end{array}$ & 0.72 & 7.24 & Maintained \\
\hline $\begin{array}{c}\text { Fair and adequate } \\
\text { compensation .....self- } \\
\text { improvement } \\
\end{array}$ & 0.74 & 6.44 & Maintained \\
\hline $\begin{array}{c}\text { Constitutionalization ......self- } \\
\text { improvement }\end{array}$ & 0.67 & 4.33 & Maintained \\
\hline $\begin{array}{c}\text { Availability of growth } \\
\text { opportunities ......self- } \\
\text { improvement } \\
\end{array}$ & 0.69 & 7.18 & Maintained \\
\hline $\begin{array}{c}\text { Social reliance ....self- } \\
\text { improvement }\end{array}$ & 0.66 & 7.56 & Maintained \\
\hline $\begin{array}{l}\text { Development of personal } \\
\text { competences .....self- }\end{array}$ & 0.71 & 7.45 & Maintained \\
\hline
\end{tabular}




\begin{tabular}{|cccc|}
\hline improvement & 0.62 & 8.98 & Maintained \\
\hline $\begin{array}{c}\text { Total life space ....self- } \\
\text { improvement }\end{array}$ & 0.64 & 8.04 & Maintained \\
\hline $\begin{array}{c}\text { Safe and healthy work } \\
\text { environment .....self- } \\
\text { improvement }\end{array}$ & 0.60 & 6.61 & Maintained \\
\hline $\begin{array}{c}\text { Social integration .....self- } \\
\text { improvement }\end{array}$ & & & \\
\hline
\end{tabular}

\section{Conclusion}

Main hypothesis: There is a statistically significant relationship between the employees' quality of work life and self-improvement.

The results from testing the main hypothesis reveal a significant, positive correlation between the quality of work life (QWL) and self-improvement of the participants. This result which can also be derived from the collective findings of sub-hypotheses suggests that the greater attention paid to the employees' quality of work life and its enhancement will lead to their gaining self-improvement of higher degrees in the organization. As the result, if managers of a given organization place more emphasis on their staffers' quality of work life, those staff members' efficiency and effectiveness, and consequently self-improvement are expected to show considerable enhancement.

Sub-hypothesis 1: There is a statistically significant relationship between fair and adequate compensation and self-improvement of the employees.

According to the results obtained, the sub-hypothesis 1 is maintained. That is, fair and adequate compensation offered to the employees correlates significantly positively with their self-improvement. Briefly put, when staff members are fairly paid on the basis of the work performed and also encouraged via incentive payments, we may experience an increased self-improvement among the employees since these two exert an influence on the staffers'better perception of the work environment.

Sub-hypothesis 2: There is a statistically significant relationship between safe and healthy working conditions and self-improvement of the employees.

This sub-hypothesis implies a direct correlation between safe and healthy work environment and selfimprovement of the employees. When staff members lack a sense of security and ceaselessly worry about the likelihood of losing their job, the atmosphere inside the organization is accordingly negatively affected and hampers them from properly discharging their responsibilities. In such an atmosphere, employees further encounter problems in their relations with each other and/or the organization. They may experience decreased levels of job satisfaction and loyalty to the organization. These may further be aggravated by their growing negative attitude to the organization and eventually lead to possibly a drastic decrease in the staffers' productivity. On the other hand, if managers value their staffers' opinions and decisions and further create an appropriate, fear-free environment for them, they may in return discharge their responsibilities to a desirable extent. Moreover, when the employees' interests are paid attention to by managers and a bed is created for their progress and promotion, a qualitative and quantitative enhancement of their activities will not seem surprising.

Sub-hypothesis3: There is a statistically significant relationship between constitutionlization and selfimprovement of the employees.

According to the results presented in Chapter 4, this hypothesis is also maintained. That is, constitutionalizationin the work environment is significantly positively correlated to the employees' selfimprovement. Walton contends that constitutionalization inside an organization is manifested in the freedom to speak out and in the rule of law rather than that of individuals.

Sub-hypothesis 4: There is a statistically significant relationship between the availability of opportunities for growth and constant security and self-improvement of the employees.

This sub-hypothesis suggests the provision of opportunities for the employees to develop their skills and competences correlates significantly positively with their self-improvement. In other words, if a person employed by a given organization knows that his/her organizational position will not be fixed rather promoted based on his/her performance, this knowledge leads to an enhanced performance and self-improvement by that employee.

Sub-hypothesis5: There is a statistically significant relationship between the employees' social reliance and self-improvement. 
This hypothesis investigates the relationship between the employee's social reliance and self-improvement. As previously mentioned, a significant, direct correlation is proven to exist between the two constructs. Social reliance is comprised of a given organization's social responsibility and the staffers' clear understanding of that organization's objectives and mission. Accordingly, it seems essential for an organization to institutionalize, by creating an appropriate cultural bed, the necessity to pay attention to social reliance and hereby to serves a role model for other organizations. By lacking social responsibilities, organizations allow employees to underestimate their work value and experience.

Sub-hypothesis 6: There is a statistically significant relationship between the employees' development of personal competences and self-improvement.

Development of personal competences of employees and its relationship with their self-improvement is another hypothesis sought here. The results obtained reveal a significant, direct correlation between these two constructs. To help develop personal competences means to provide opportunities for the exercise by employees of independence and self-control at work, for taking advantage of various skills development and for gaining access to work-related information.

Sub-hypothesis 7: There is a statistically significant relationship between total life space and self-improvement of the employees.

According to the results, the present hypothesis is maintained. The indicators constituting this QWL dimension are,among others, establishment of a balance between personal and social life, playing different social roles and pursuing studies. Walton believes that by creating a balance between a worker's time at work and time for family an ultimate balance can be established between his/her work and non-work life. And this suggests the direct relationship between one's work and total life space.

Sub-hypothesis 8: There is a statistically significant relationship between social integration and selfimprovement of the employees.

The last hypothesis of this study seeks the association between social integration and self-improvement of the participants. The results obtained signify a direct correlation between these two constructs. This dimension of the quality of work life comprisessuch indicators as the absence of discrimination among staff members and rather presence of mutual trust and support among them. According to Walton, having no prejudice against race, sex and movement towards the top of organizational hierarchy, creating a sense of sociability in organizations, individuals' freedom to speak their opinions and feelings out and finally creating a work environment which promotes employees' sense of belonging to the organization and, in return, the organization's need for its employees all are among the issues resulting in the organization's social integration.

\section{Reference}

[1]. Balcombe, K., Davidova, S. and Latruffe, L. (2008) The use of bootstrapped Malmquist indices to reassess productivity change findings: an application to a sample of Polish farms, Applied Economics, 40, 2055-61.

[2]. Dehghan Nayeri N, Salehi T, Asadi Noughabi A. (2009). Assessing the quality of work life, productivity of nurses and their relationship. Journal of Nursing Research. 3(8,9): 27-33. [ In Persian].

[3]. Kumar, S. And Gulati, R. (2010). Measuring efficiency, effectiveness and performance of Indian public sector banks. Journal of Productivity and Performance Management, 59(1), 51-74.

[4]. Lee, B. L., Worthington, A. and Leong, W.-H. (2010) Malmquist indices of pre and post-deregulation productivity, efficiency and technological change in the Singaporean banking sector, Singapore Economic Review, 55, 599-618.

[5]. Mohammadi A, Sarhangi F, Ebadi A, Daneshmandi M, Reiisifar A, Amiri A, Hajamini Z.(2011). Relationship between psychological problems and quality of work life of Intensive Care Units Nurses. Iranian Journal of Critical Care Nursing. 4(3): 135-140. [In Persian]

[6]. Pammolli, F., Magazzini, L. and Riccaboni, M. (2011), The Productivity Crisis in Pharmaceutical R\&D, Nature Reviews Drug Discovery $10,428-438$.

[7]. Syverson, Chad (2010), "What determines productivity?" mimeo, University of Chicago.

[8]. Taali H. [A study of impact of quality of life work on productivity of employees of all banks of Iran]. MA. Dissertation. Allameh Tabatabaei University, 1996: 92-112. (Persian).

[9]. Zheng, W, Yang, B \& McLean, G.N (2010). Linking organizational culture, structure, strategy, and organizational effectiveness: Mediating role of knowledge management, Journal of Business Research, 2010, Vol63, p764. 